\title{
Authoritarianism, trauma, and insecure bonds during the Greek economic crisis
}

\author{
Antigonos Sochos ${ }^{1}$ \\ Published online: 10 January 2019 \\ (C) The Author(s) 2019, corrected publication March/2019
}

\begin{abstract}
This correlational study investigated the link between authoritarian attitudes, psychosocial trauma, and attachment insecurity in the context of a significant community and personal threat - the recent economic crisis in Greece. The study utilised a large community sample and five self-report measures - Right-Wing Authoritarianism Scale-S, Social Group Attachment Scale, Relationship Questionnaire, Perceived Cohesion Scale, and Impact of Events Scale-R. It was hypothesised that authoritarianism would be independently linked with insecurity in two types of bond (person-to-person and person-to-state) via the experience of post-traumatic stress and perceptions of social cohesion. Structural Equation Modelling indices suggested that the model had a very good fit.
\end{abstract}

Keywords Authoritarianism · Trauma $\cdot$ Attachment $\cdot$ Social cohesion $\cdot$ Economic crisis

\section{The Greek Economic Crisis and the Rise of Right-Wing Authoritarianism}

The global economic crisis of 2008 was manifested in Europe as the "crisis of the Euro", hitting hard many communities, particularly those of the European South. The country mostly affected was Greece. Unable to deal with a prohibitive national debt, Greece became in effect bankrupt and in 2010 was forced to borrow from a "troika" of international lenders - the European Central Bank, the European Union, and the International Monetary Fund - in exchange for harsh austerity measures. As the income of the population shrank, so did its spending capacity, throwing the country into a spiral of ever deepening recession. At the time of data collection and since the beginning of the crisis, average household income was reduced by over $40 \%$, unemployment soared to $27 \%$ (56\% among the young), and public spending for health and social care was cut by approximately 50\% exposing the great majority of those in need to dangerously sub-standard care. Malaria was nearly re-established in the country, HIV infections increased by $200 \%$, and all major mental health indices suggested a highly distressed population (Economou et al.

Antigonos Sochos

antigonos.sochos@beds.ac.uk

1 Department of Psychology, University of Bedfordshire, Luton LU1 3JU, UK
2013; Anagnostopoulos and Soumaki 2013; Kentikelenis et al. 2011). Findings from the current sample presented elsewhere suggested that almost $60 \%$ of participants had reported severe post-traumatic stress (Sochos 2018).

It is not surprising that in the context of such devastation, the great majority of the population perceived major sociopolitical institutions as failing and trust in them was almost entirely lost (Public Opinion Analysis Sector of the European Commission 2012). The two political parties that had shared power between them in the past 40 years collapsed, to be replaced by a new left-wing government, which, despite its strong anti-austerity rhetoric while in opposition, followed exactly the same policies further damaging the economy and undermining public trust in institutions. Greek intellectuals and public commentators across the political spectrum described this state of affairs as a decline, distinguishing it from the notion of a crisis, and argued that the nation is facing an existential threat (Markezinis 2017; Pierrakakis 2017). The country seems to experience what Sztompka (2000) has described as traumatic social change.

In the midst of it all, a new socio-political force emerged, proclaiming that it would regain the lost national pride, severely punish the internal and external enemies of the motherland, and return to the ancient and eternal traditions of the Nation. Before the crisis Golden Dawn, the Greek Neo-Nazi party, was a small organization in the fringes of the extreme right, with no more than a few thousand supporters nationwide. In the last two national elections, it obtained almost 7\% 
of the vote, becoming the third largest political party in the Greek parliament. In addition to announcing a return to the glory of the past, Golden Dawn conducts significant "public protection" work on the ground. Party gangs attempt to "restore social order" in deprived, disorganised, and crimeridden neighbourhoods by scapegoating, assaulting, and occasionally killing impoverished immigrants (BBC News 2013). At the same time, they often help elderly Greeks with everyday errands or organise soup kitchens for the poor Greeks, convincing some of the highly distressed and scared that the covert sociopathy of Golden Dawn is a protective force defending the hard done by ordinary folk.

Most of all, Golden Dawn is perceived to protect against threats to social and national identity, stirred-up by the brutality of the foreign lenders and the local elite, malignant representations of a chaotic immigrant influx, and negative stereotypes of the country and its citizens in the international press e.g. Greeks as lazy, ouzo-drinkers (Tzogopoulos 2016). The rise of Golden Dawn is just one example among many suggesting a general trend towards right-wing authoritarianism in Europe and the USA in the years following the global economic crisis. Far-right parties and political movements driven by xenophobic and racist discourses have been on the rise in France, Italy, Germany, Austria, Holland, Hungary, and elsewhere in Europe as well as in the US. These developments are consistent with research studies evidencing that economic threats can lead to greater authoritarianism (Rickert 1998; Sales 1973). The present study aimed to enhance our understanding of that upsurge by focusing on the Greek case and researching the links between right-wing authoritarianism, disrupted social bonding, and traumatisation due to the recent economic crisis.

\section{Authoritarianism, Trauma, and Human Bonds}

Authoritarianism has long been a concept of great interest among social scientists. Originally introduced by Adorno and colleagues in reference to a particular personality structure (Adorno et al. 1950), it has been extensively commented upon, criticised, and revised by numerous scholars (Altemeyer 1981; Duckitt 1989; Feldman 2003). Contemporary researchers have abandoned the Freudian paradigm informing the initial formulations and have re-situated the concept within a social-cognitive framework. Authoritarianism is now largely understood as a set of socio-political attitudes that include three main components - submission to authority, the uncritical acceptance of tradition, and hostility towards those who question authority and tradition (Altemeyer 1981). Although the concept of authoritarianism has been linked with far-right political ideology since its early days, some have argued that it also exists on the left (Durrheim 1997). Initial efforts were unable to provide empirical support for this claim
(Altemeyer 1996), but later studies have shown that leftwing authoritarianism is a valid construct describing attitudes found in certain groups of the far-left, such as stalinists (Van Hiel et al. 2006). The present study is only concerned with right-wing authoritarianism, as it is primarily this type that has been fuelled by the Greek economic crisis.

Theorists argue that authoritarian attitudes come to the fore when individuals with a particular disposition experience specific types of threat (Cohrs, 2013; Onraet and Van Hiel 2013). It is suggested that individuals express authoritarian attitudes not only when they encounter a personal threat but also a threat to their collective identity and bonds with their social groups. Some authors claim that those with an authoritarian disposition perceive certain events as a danger to social cohesion and consequently their group identification, and that the authoritarian response itself aims to restore personal as well as collective security (Duckitt 1989; Kreindler 2005). Feldman (2003) suggests that threats to social cohesion are perceived as threats to social order by individuals who value social conformity over personal autonomy, eliciting a reaction of intolerance and prejudice.

It seems that, since its early days, the concept of authoritarianism has also been linked with the notion of trauma. According to the initial formulation, authoritarian individuals tend to have experienced harsh and threatening parenting as children, with deleterious long-lasting effects (Adorno et al. 1950; Fromm 1941). Such early experiences have been thought to often result in lifelong overwhelming fear and hostility towards the aggressive parent, that is defensively repressed and displaced onto vulnerable social groups like immigrants and ethnic minorities. More recently, arguing from a social-cognitive perspective, Oesterreich (2005) claimed that at the heart of authoritarianism lies a psychological insecurity brought about by a different type of developmental trauma excessive parental control and restricted child autonomy.

According to Oesterreich, such early experiences prevent individuals from developing adequate coping competencies, rendering them vulnerable to feelings of overwhelming anxiety even in the face of minor difficulty. As they find it hard to cope with life, these individuals feel increasingly more incompetent and insecure, seeking refuge in parental substitutes - allpowerful leaders and unchallenged psychosocial arrangements. Since they tend to perceive diversity in perspective and open communication as threats to their fragile sense of self, these individuals often tend to turn to authoritarian ideologies for protection. It seems that only the uncritical acceptance of absolute truths and the unconditional obedience to power can provide them with a tentative sense of safety in what they perceive to be an unpredictable and dangerous world. Oesterreich's notion of authoritarian insecurity seems to resemble closely that of attachment insecurity, a concept of great significance in social and developmental psychology in the past 40 years. Yet, the author never located his work explicitely within the attachment framework. 
The link between authoritarianism and trauma also appears in non-developmental research. Relatively strong authoritarian attitudes have been found among 9/11 survivors (Bonanno and Jost 2006) while a wealth of historical evidence suggests that individuals and communities often turn to authoritarian ideologies after the occurrence of painful and overwhelming events (Besel 1984; McCann and Stewin 1987). Studies on social memory indicate that totalitarian modes of thinking thrive in traumatised communities where failed social institutions are unable to provide a sense of collective protection and containment (Klímová 2011; Ray 2006). This literature seems to suggest that authoritarianism is a type of traumatic response: it is elicited by the experience of a real threat to individual and/or collective well-being, it involves a persistently exaggerated perception of that threat, and it is facilitated by past and/or present ruptures in human bonding. Understanding the quality of human bonds, both interpersonal and collective, seems, therefore, critical in understanding authoritarianism and the psychosocial traumatisation associated with it. To conceptualise human bonding, the present study draws on attachment theory.

\section{Main Ideas in Attachment Theory}

In the past four decades attachment theory has become very influential in the study of psychosocial development and human relationships (Cassidy and Shaver 2008). According to Bowlby (1980), the need to establish close emotional bonds with important others is a fundamental human disposition with clear evolutionary advantages - it reduces child mortality, facilitates support exchange between adults, and enhances individual competence. A central concept in the theory is that of attachment security. When caregivers are systematically available and responsive, the child and later adult will have the tendency to form secure emotional bonds with others; when support provision is disrupted the individual will tend to form insecure bonds. Brennan et al. (1998) argue that attachment is underlain by two fundamental dimensions - anxiety and avoidance. Securely attached individuals are low in both dimensions while the insecurely attached report high scores in one (avoidant or anxious attachment style) or both (fearful attachment style). Attachment style originates in actual interactions with caregivers and becomes an individual disposition through the internalisations of such interactions and the formation of attachment mental representations (Bretherton and Munholland 2008).

As the main function of the attachment system is to protect from danger, physical or emotional, it is not surprising that attachment style is linked with the capacity of individuals to deal with threats. Those high in attachment anxiety tend to be overvigilant, exaggerate the seriousness of a threat and the likelihood of negative outcomes, rate their own coping capacity as inadequate, and report high levels of distress during and after stressful events (Ein-Dor et al. 2011). On the other hand, individuals high in avoidance tend to divert attention from threatening signals, minimise their seriousness, suppress threat-related thoughts, avoid appraising events as threatening, expect better outcomes when feelings of vulnerability are suppressed, avoid asking for help when in distress, and take rapid self-protective action without coordinating with others when the threat is imminent (Mikulincer and Shaver 2007).

These findings are consistent with studies highlighting the role of attachment security in the experience of traumatic events. A fearful attachment style is an important contributor in the development of post-traumatic stress (Woodhouse et al. 2015), while a secure attachment relationship with a caregiver can protect a child from the worst effects of child abuse (Schofield and Beek 2014). As a supportive emotional bond with a parent or adult peer helps the individual to make sense of threatening and potentially traumatic events (Cox et al. 2016), when the perpetrator is the intimate other him/herself, the source of threat will be identical with the source of protection and the attachment system will be disorganised (Yellin and White 2012). Attachment disorganisation is defined by a strong tendency to both cling onto and avoid the attachment figure, a tendency prevalent among fearful individuals. Moreover, research suggests that an insecure attachment style compromises the capacity to elicit supportive responses not only from intimate others and also from one's social network (Mikulincer and Shaver 2009). Perceptions of low social support and low community cohesion have been linked with high levels of post-traumatic stress in both individual and mass traumas (Johns et al. 2012; Lê et al. 2013).

In recent decades authors have extended attachment research beyond the study of intimate relationships suggesting that the attachment concept may be relevant in understanding group and wider social phenomena. Compared to the secure, insecurely attached individuals are more likely to form incohesive groups, find interactions with both ingroup and outgroup members threatening, have negative emotions elicited by the ingroup, report negative group memories, and engage in more negative exchange with the outgroup (Mikulincer and Shaver 2001; Rom and Mikulincer 2003). Building on Bowlby's (1982) initial claim, authors have argued that social groups and social institutions function as attachment objects that human beings look for safety and protection to (Mayseless and Popper 2007; Smith et al. 1999). Empirical evidence suggests that the fundamental dimensions underlying individual to group attachment are the same as those underlying interpersonal attachment - avoidance and anxiety (Rom and Mikulincer 2003; Smith et al. 1999). Moreover, as systems of belief are what essentially defines the identity of social groups and social institutions (Bar-Tal 
2000), it has been argued that attachment to the group in effect suggests attachment to the group's dominant ideological system (Sochos 2014).

Research has found clear links between attachment insecurity and authoritarianism. Weber and Federico (2007) report that anxiously attached individuals are more likely to adopt an authoritarian stance when their perception of the world as dangerous and unpredictable is relatively strong. A number of studies also support a connection between attachment insecurity and attitudes of intolerance such as homophobia (Gormley and Lopez 2010), prejudice towards disability (Vilchinsky et al. 2010), far-right conservatism (Weise et al. 2008), and a hawkish approach to foreign policy (Gillath and Hart 2010).

\section{Aims and Hypotheses}

The present study aimed to investigate the emergence of rightwing authoritarianism in the context of psychosocial trauma (the recent socio-economic crisis in Greece) and explore that link from an attachment theory perspective. Although high levels of post-traumatic stress have been evidenced in small social groups after an economic misfortune (Freshman 2012), socio-psychological research focused on trauma has rarely involved large community samples undergoing an economic crisis. Utilising such a sample, the present study intended to empirically confirm whether, in the context of threats that are both personal and collective, insecure attachment (interpersonal and collective) was a predisposing factor towards the development of authoritarian attitudes. In particular, a pathway model was hypothesised according to which attachment to the national state and to significant others would independently predict right-wing authoritarianism through direct and indirect pathways to post-traumatic stress elicited by the crisis and perceptions of social cohesion. The following pathways were expected to be significant: attachment to person $\rightarrow$ social cohesion $\rightarrow$ post-traumatic stress $\rightarrow$ authoritarianism $\left(\mathrm{H}_{1}\right)$ and attachment to state $\rightarrow$ social cohesion $\rightarrow$ post-traumatic stress $\rightarrow$ authoritarianism $\left(\mathrm{H}_{2}\right)$. Direct pathways from both types of attachment to authoritarianism were also hypothesised $\left(\mathrm{H}_{3}\right)$.

Although attachment style is regarded as a relatively stable characteristic and authoritarian attitudes are thought of as responses to specific individual and collective threats, it is also possible that authoritarianism, perhaps enhanced by the crisis, had an impact on the way individuals related to others as well as to the state institutions. Even though the correlational nature of the present study renders any causal hypotheses very tentative, it was expected that the hypothesised model above would fit the data better than an alternative model including pathways from authoritarianism to the two attachment domains, including indirect links via social cohesion and posttraumatic stress.

\section{Method}

\section{Design}

A questionnaire-based correlational design was employed measuring right-wing authoritarianism, interpersonal attachment style, attachment to the group, perceived social cohesion, and post-traumatic stress. Data were collected between March and July 2013 in a working/lower middle class borough of western Athens (Aspropyrgos) with a population of around 30,000. In this borough, Golden Dawn obtained its second highest percentage (14.5\%) during the 2012 and 2015 elections and its highest percentage (17\%) in the 2014 local elections (Mesogianews 2015).

\section{Participants}

A convenience non-probability sample of 1208 participants was recruited, on the basis of easiness of access. Being a borough resident and a Greek national were the only inclusion criteria. Forty-nine percent were men and mean age was 36 $(s d=12.2)$. Sixty percent were fully employed, $9.6 \%$ were employed part-time, $26.4 \%$ were unemployed, and were $3.7 \%$ pensioners. Over $43 \%$ were married, $6.2 \%$ were divorced, $15.5 \%$ were in long-term non-marital relationship, $5 \%$ were widows/ers, and $33.9 \%$ were single. Forty-one percent were university graduates, $50.1 \%$ had completed secondary education, $5.6 \%$ had completed lower secondary education, and $3.8 \%$ had completed primary school. The sample had sufficient statistical power, according to the standards set in the SEM literature (Wolf et al. 2013). The convenience nature of the sample and the fact that key demographic variables were associated with post-traumatic stress in this study as presented elsewhere (Sochos, 2018) may have influenced the current analyses.

\section{Measures}

Other than the Impact of Events Scale, none of the present measures was available in Greek when data collection begun, so they had to be translated by two bi-lingual speakers using the method of back translation (Brislin 1970).

Right-Wing Authoritarianism Scale - Short Version (RWASS; Zakrisson 2005). This is a short version of the Right-Wing Authoritarian Scale (Altemeyer 1998), validated against measures of social dominance orientation, ethnic tolerance, racism, and sexism (Zakrisson 2005). In the present study, the scale was adapted to capture dominant themes in the current right-wing authoritarian discourse emerging in the context of the Greek crisis The adapted Greek version had 12 items (see Appendix). Five of the original items $(4,8,10,11,15)$ were not included at all as they did not seem directly relevant and 
the questionnaire needed to be kept brief. Item 8 called for the defence of the state and the church, but in the current far-right discourse in Greece these institutions have been blamed for the crisis and forcefully attacked. The terms Bible and religion in item 10 have similar connotations. Finally, the terms radical and immoral in item 11 are opposites in that discourse - the far-right describe themselves as radicals fighting the immoral political establishment - while the use of the term untraditional in item 4 presents related problems.

Moreover, three original items were slightly modified. In original item 1 the terms radical and immoral were replaced by the term democracy for the reasons explained above (Greek item 1), while in original item 13 the terms crime and sexual immorality were replaced by the term immigrants (Greek item 4). In Golden Dawn discourse crime refers either to the crimes of the political establishment, corruption and submission to the foreign lenders, or to common everyday crime only committed by immigrants. In original item 5 sexual immorality, abortion, and pornography are not important themes in that discourse, so the term family was used instead (Greek item 5). Finally two items were added aiming to capture main concerns of the current Greek far-right: national superiority vs. foreign conspiracy (Greek item 8) and protection of the fatherland vs. corrosive democracy (Greek item number 12).

Social Group Attachment Scale (SGAS; Smith et al. 1999) This is a 25-item questionnaire assessing attachment to the social group on a five-point Likert scale (1-5). Empirical evidence suggests that a two-factor structure underlies the instrument (avoidance and anxiety) and supports its concurrent and discriminant validity against measures of collective self-esteem, in-group evaluation, and group conflict (Rom and Mikulincer 2003; Smith et al. 1999). In the present study the questionnaire was adapted to assess attachment to the Greek state (see Appendix). The term state refers to the formal institutional aspects of the national group that aim to protect the life of both individuals and the group, so it was a very appropriate focus of study.

\section{Relationship Questionnaire (RQ; Bartholomew and Horowitz} 1991) This is a widely used self-report questionnaire measuring adult attachment style with good convergent, discriminant, and predictive validity (Griffin \& Bartholomew, 1994). It consists of four small paragraphs, each portraying one of four attachment styles: secure, dismissing, preoccupied, and fearful. Participants are asked to indicate the extent to which each of these statements describe themselves, using a 7-point Likert scale.

Impact of Events Scale-Revised (IES-R; Weiss and Marmar 1997) This is a 22-item extensively used questionnaire measuring symptoms of post-traumatic stress in relation to a specific traumatic event, across three subscales (Intrusion,
Avoidance, and Hyperarousal). A five-point Likert scale (04 ) is used. It should be used as a screening rather than diagnostic instrument, with high scores suggest the possibility of clinical or subclinical post-traumatic stress (King et al. 2009). Participants were asked to identify the most distressing event they had experienced in relation to the economic crisis and report symptoms associated with that event only. Events recorded typically included drastic income reduction through salary/pension cuts, redundancy, and loss of business. IES-R has been used with Greek participants before, presenting satisfactory internal consistency, good test-retest reliability, and evidence for construct validity against measures of anxiety and depression (Mystakidou et al. 2007). In the current study scale reliability was excellent (alpha $=.96)$.

Perceived Cohesion Scale (PCS; Bollen and Hoyle 1990) This is a six-item questionnaire measuring how individuals perceive their membership to a social group on a five-point Likert scale (1-5). It consists of two subscales - sense of belonging (the extent to which an individual feels s/he belongs to a group) and feelings of moral (the extent to which the individual feels positive about belonging to a group). The instrument has been validated with a variety of social groups including college students, city residents, and small experimental groups (Chin et al. 1999).

\section{Procedure}

Participants were contacted in public places (e.g. the market, coffee shops) by an appropriately trained research assistant between March and July 2013. The study received ethical clearance from the Psychology Department of the University of Bedfordshire, UK

\section{Results}

In the first phase of data analysis the factorial validity of the newly translated scales was tested, using confirmatory factor analysis (CFA) in AMOS-21. Firstly, the two-component structure of SGAS as reported by Smith et al. (1999) was tested. Eight items had acceptable weights and were retained in the model - 1, 4, 9, 11 for Avoidance (alpha = .58 composite reliability $/ \mathrm{CR}=.42$ ) and 10, 12, 21, 24 for Anxiety (alpha = $.69, \mathrm{CR}=.48$; see Fig. 1). The model had a very good fit $(\mathrm{CFI}=.96 ; \mathrm{IFI}=.96 ; \mathrm{NFI}=.95 ; \mathrm{RMSEA}=.05$; $\left.\mathrm{X}^{2}{ }_{18}=.90 .15, p<.001\right)$, alpha for the whole scale was .72 and the two components were positively correlated $(r=.42$, $p<.001)$.

The three-component structure of right-wing authoritarianism presented by Altemeyer (1981) was also tested. RWAS-S items 2, 8, and 10 had very low weights and were removed, leaving items 3, 5, 9 for 
Fig. 1 Factor structure of the Social Group Attachment Scale, includingthe item weights

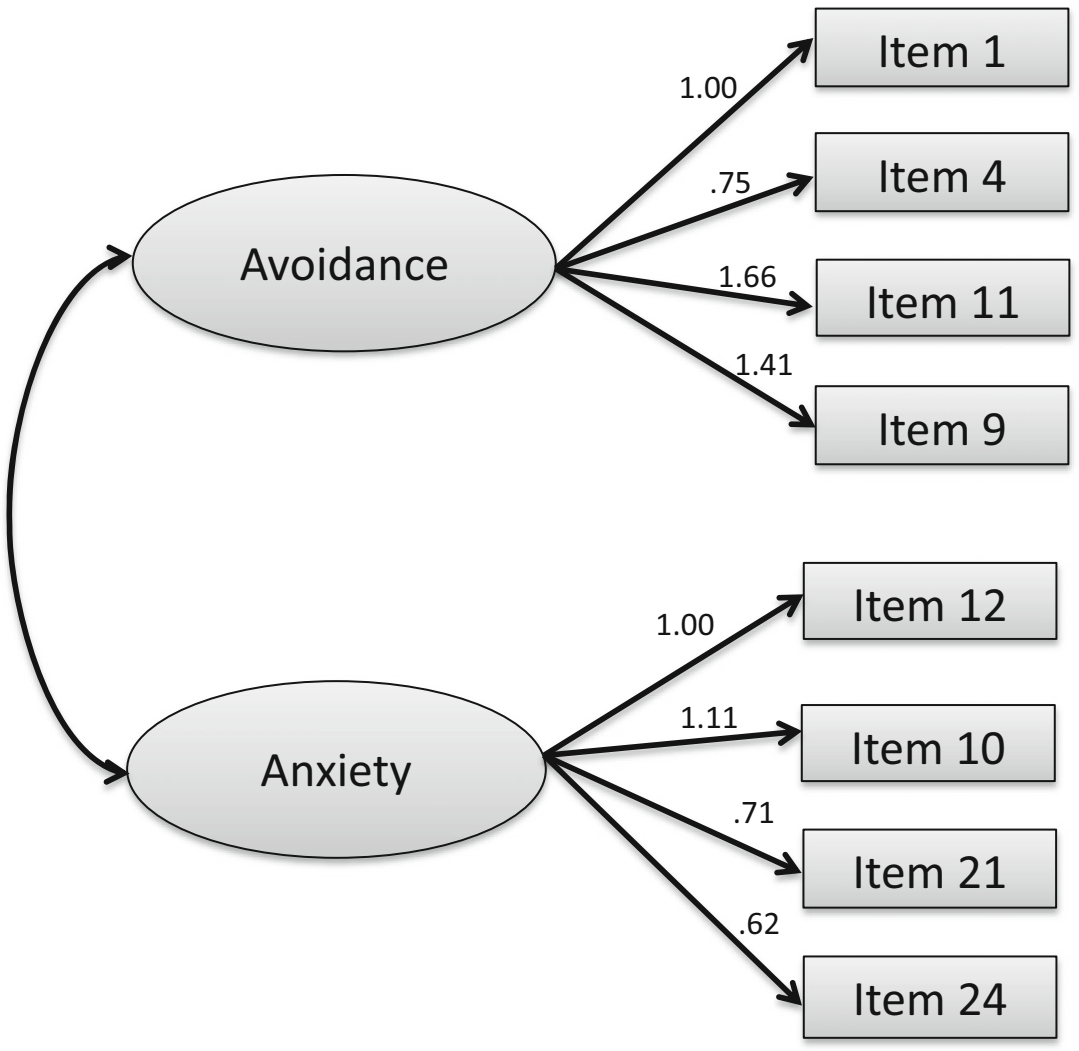

conventionalism (alpha $=.75, \mathrm{CR}=.76), 1,6,7$ for authoritarian submission (alpha $=.29, \mathrm{CR}=.42$ ), and 4,11 , 12 for authoritarian aggression (alpha $=.61, \mathrm{CR}=.65$, see Fig. 2). The final model presented a very good fit $\left(\mathrm{GFI}=.97 ; \mathrm{CFI}=.95 ; \mathrm{IFI}=.95 ; \mathrm{RMSEA}=.06 ; \mathrm{x}_{23}^{2}=\right.$ $143.62, p<.001)$ and the alpha for the whole scale was .76. Very tentatively, correlation coefficients were $\mathrm{r}=.42(p<.001)$ between conventionalism and authoritarian submission, $r=.48(p<.001)$ between conventionalism and aggression, and $r=.49(p<.001)$ between submission and aggression. Moreover, testing the factor structure of the SCS, the model had excellent fit ( GFI $=.99 ; \quad$ CFI $=.99 ; \quad$ IF I $=.99 ; \quad$ NFI $=.99$; RMSEA $\left.=.04 ; \mathrm{x}^{2}=.25 .04, p=.001\right)$ and the two components correlated positively as predicted $(r=.5$, $p<.001)$. Alphas were .88 for sense of belonging $(\mathrm{CR}=.75), .65$ for feelings of morale $(\mathrm{CR}=.58)$ and .79 for the whole scale. Finally, correlations between the single-item scales of the RQ were consistent with theory: fearful style was related to both preoccupied $(r=.37, p<.001)$ and dismissing $(r=.23, p<.001)$, while the secure correlated very weakly with the other styles (all $\mathrm{r} s<.08, p<.05$ ).

After the factor structure of all newly translated instruments had been investigated (see Table 1 for means and standard deviations), the hypothesised model was tested using Structural Equation
Modelling (see Fig. 3). High scores in either of the exogenous variables indicated insecure attachment. The model had a very good fit $(\mathrm{GFI}=.96 ; \mathrm{CFI}=.95$; $\mathrm{IFI}=.95 ; \mathrm{NFI}=.94 ; \mathrm{RMSEA}=.05 ; \mathrm{AIC}=375.46$; $\left.\mathrm{BIC}=558.21 ; \mathrm{x}^{2}{ }_{\mathbf{7 0}}=326.46, p<.001\right)$. However, three pathways (Group Attachment $\rightarrow$ Authoritarianism $(p=.121)$, Interpersonal Attachment $\rightarrow$ Social Cohesion $(p=.881)$, and Social Cohesion $\rightarrow$ PostTraumatic Stress $(p=.069)$ were non-significant and subsequently removed from the model. According to the final model (see Table 2 for direct and indirect effects), interpersonal attachment presented a primarily direct link with authoritarianism, so that the insecurely attached reported stronger authoritarian attitudes. A weaker indirect pathway via post-traumatic stress was also observed, indicating that the insecurely attached also developed authoritarian attitudes as they experienced post-traumatic stress in relation to the economic crisis. Insecure attachment to the national state led to lower authoritarianism as individuals perceived relatively low social cohesion and to high authoritarianism as individuals perceived high post-traumatic stress.

Finally, an alternative model was tested suggesting a reverse causality from authoritarianism to attachment including the exact pathways observed in the original model, but reversed; the fit indices were GFI =.96; 
Fig. 2 Factor structure of RightWing Authoritarianism Scale Short Version, including the item weights

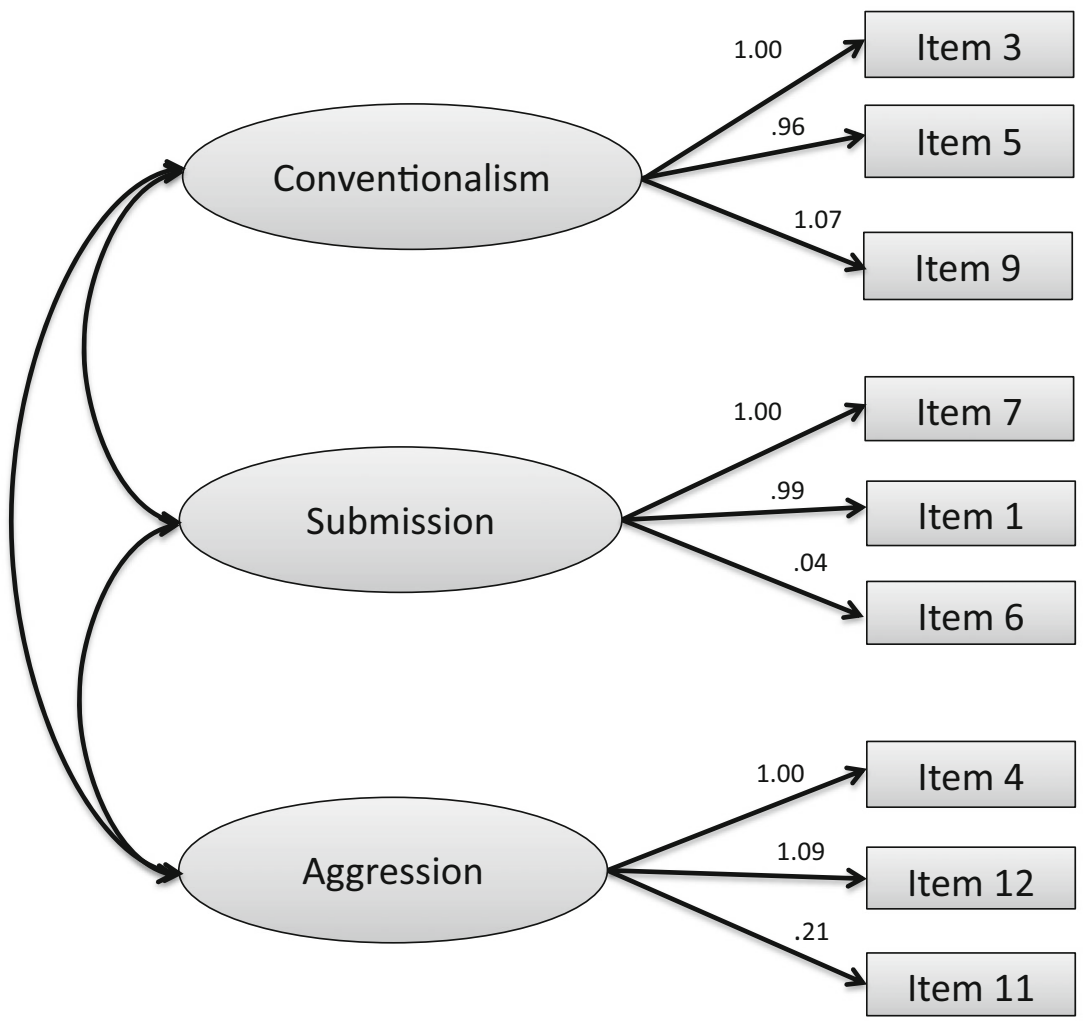

$\mathrm{CFI}=.95 ; \mathrm{IFI}=.95 ; \mathrm{NFI}=.93 ; \mathrm{RMSEA}=.06 ; \mathrm{AIC}=$ 425.84; $\mathrm{BIC}=599.13 ; \mathrm{x}^{2}{ }_{\mathbf{7 0}}=357.84, p<.001$. When the alternative model also included the links Interpersonal Attachment $\rightarrow$ Social Cohesion and Social Cohesion $\rightarrow$ Post-Traumatic Stress, which now were significant, fit indices were $\mathrm{GFI}=.96$; $\mathrm{CFI}=.95$; $\mathrm{IFI}=.95 ; \mathrm{NFI}=.94 ; \mathrm{RMSEA}=.05 ; \mathrm{AIC}=398.96$; $\mathrm{BIC}=582.44 ; \mathrm{x}^{2}{ }_{69}=326.96, p<.001$. In both cases the AIC and BIC indices of the alternative model were larger than those of the initial model, suggesting that the latter had a better fit.

Table 1 Means and standard deviations of study scales

\begin{tabular}{lll}
\hline Scale & $\mathrm{M}$ & $\mathrm{SD}$ \\
\hline Secure/RQ & 21.77 & 3.35 \\
Fearful/RQ & 2.26 & 1.16 \\
Dismissing/RQ & 2.53 & 1.33 \\
Preoccupied/RQ & 2.10 & 1.12 \\
Anxiety/SGAS & 15.47 & 2.72 \\
Avoidance/SGAS & 13.76 & 2.70 \\
Submission/RWAS-S & 8.92 & 2.38 \\
Conventionalism/RWAS-S & 10.84 & 2.50 \\
Aggression/RWAS-S & 8.36 & 2.53 \\
Belonging/PCS & 12.21 & 2.98 \\
Morale/PCS & 11.03 & 3.86 \\
IES-R & 38.56 & 21.03 \\
\hline
\end{tabular}

\section{Discussion}

A pathway model was hypothesised according to which, in circumstances of significant socio-economic turbulence, the expression of authoritarian attitudes would be linked to insecure individual-to-state and person-to-person attachment through the experience of relatively low social cohesion and significant posttraumatic stress related to the crisis. Although specific hypothesised pathways were not significant, the overall model was confirmed, suggesting that authoritarianism was predicted by insecure person-to-person attachment both directly and via the experience of high posttraumatic stress and by insecure person-to-state attachment indirectly, via the experience of high posttraumatic stress and the perception of high social cohesion. The hypothesised pathways linking state attachment and authoritarianism, interpersonal attachment and social cohesion, and social cohesion and posttraumatic stress were not confirmed.

The present findings are in agreement with both historical (McCann and Stewin 1987) and sociopsychological (Marlin 2015) research suggesting that authoritarianism is more likely to develop in social environments permeated by disruptions in human relatedness. They are also consistent with previous studies reporting a link between authoritarian attitudes and the quality of interpersonal attachment more specifically 


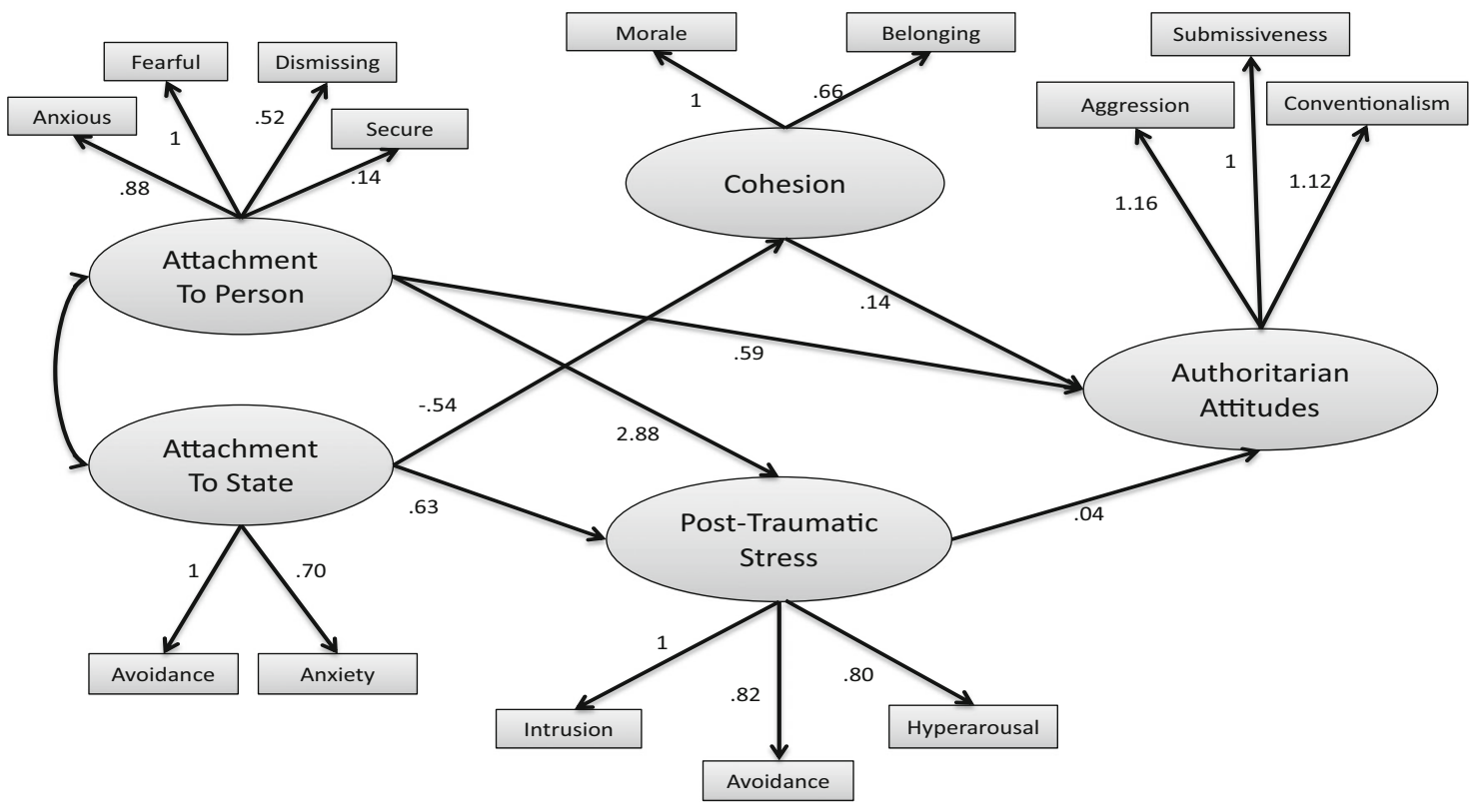

Fig. 3 Final mode, including unstandardised direct effects

(Weber and Federico 2007) and lend further support to the idea that the concept of authoritarian disposition and its hypothesised developmental antecedents may be linked with that of attachment insecurity. Moreover, the current study confirms the distinction between interpersonal and person-to-institution/group attachment made in previous research (Mayseless and Popper 2007; Smith et al. 1999) and identifies different routes via which insecurity in the two attachment domains may lead to authoritarianism. Post-traumatic stress was the only mediating variable to link both attachment domains with authoritarianism, suggesting that an individual's inability to feel protected against perceived threats to life by an essential social institution is almost as important as the inability to feel supported and understood by intimate others.

Considering that in this study, post-traumatic stress was measured only in relation to the socio-economic crisis and that the Greek state was a primary contributor to that crisis, the source of threat and the expected source of protection were one and the same. According to relevant research, the perception of another meant to be protective as threatening typically underpins attachment disorganisation and trauma (Yellin and White 2012). Perhaps a similar process is set off also when a collective, as opposed to interpersonal, source of expected security becomes hostile, as the Greek state has been towards its citizens during the crisis. The high levels of post-traumatic stress observed in the present sample (Sochos 2018) and the link between state aggression and social disorganisation frequently evidenced in previous studies (Malley-Morrison 2009) are consistent with such a hypothesis. Future research needs to clarify further the psycho-social process involved in institutional traumatisation from an attachment theory perspective.
Table 2 Estimated

unstandardised effects in the final model (all-zero effects not included). The $p$ values in all nonzero effects were $<.001$

\begin{tabular}{llll}
\hline Effect & Total Effect & Direct Effect & Indirect Effect \\
\hline On Social Cohesion & & & \\
$\quad$ From Attachment to State & -.54 & -.54 & .00 \\
On Post-Traumatic Stress & & & \\
From Attachment to State & .63 & .63 & .00 \\
From Attachment to Person & 2.88 & 2.88 & .00 \\
On Authoritarianism & & & -.06 (-.07 via SC, .02 via PTS) \\
From Attachment to State & -.06 & .00 & .08 \\
From Attachment to Person & .67 & .59 & .00 \\
From Social Cohesion & .14 & .14 & .00 \\
From Post-Traumatic Stress & .04 & .04 & \\
\hline
\end{tabular}


According to the current findings, interpersonal but not individual-to-state insecurity had a direct link to authoritarianism, an observation consistent with both classic and contemporary conceptualisations of the authoritarian disposition as being rooted in formative interpersonal relationships (Adorno et al. 1950; Oesterreich 2005). As the hypothesised direct link between authoritarianism and attachment to the state was not confirmed, the findings seem to suggest that collective attachment requires a particular collective experience (that is, particular perceptions of social cohesion or institutional traumatisation) to feed into the development of authoritarian attitudes.

When reflecting on the current findings, the limitations of the study need to be considered, particularly the lack of previous validation of the scales with a Greek sample. Low alphas observed in some of the subscales call for caution. Cronbach's alpha has been criticised as being too conservative and susceptible to the influence of low item numbers (Sijtsma and van der Ark 2015). Indeed, in the present study all subscales attaining low alphas included only a few items, while alphas in whole scales which also included more items were satisfactory. Moreover, subscales in this study were not used in isolation but as part of factors attaining very good fit using SEM, a method more robust than Cronbach's alpha. Nonetheless, findings should be approached with caution and further research should confirm the reliability and validity of these scales, particularly as they are set to measure complex constructs and cross disciplinary boundaries. For example, avoidance to the state, a complicated and multifaceted concept to capture empirically, may require more than adapting a scale originally designed to measure avoidance in interpersonal relationships. Similarly difficult may be capturing authoritarian submission and aggression in a new socio-cultural context where concerns about immigration spread across the political spectrum and institutions traditionally friendly to the far right, such as mainstream conservatism and the church establishment, are now seen as suspect.

The present study suggests that insecurity in the bond with the state can lead to authoritarianism indirectly, via the experience of traumatisation and perceptions of social cohesion. This, however, involved two different rather than one single pathway as it was hypothesised. Perhaps the construct of collective attachment lies behind the link between post-traumatic stress and perceptions of social cohesion, as suggested in previous studies (Johns et al. 2012). If this is true, when attachment to a major institution is entered into the model as occurred in the present study, the link between social cohesion and post-traumatic stress will become nonsignificant.
Nonetheless, the positive relationship observed between perceived cohesion and authoritarianism, however weak, appears to contradict the claim that authoritarianism emerges as a response to threatening perceptions of low social cohesiveness (Duckitt 1989; Feldman 2003). As data were collected after Golden Dawn had already been established as a significant political force both nationally in the particular borough, its ultra-nationalistic discourse may have inflated the sense of morale and belonging among sympathisers, resulting in a positive association between perceptions of social cohesion and authoritarian attitudes. However, as the present study did not assess voting behaviour or party affiliation, the extent of the link between authoritarianism and support for Golden Dawn or any other politicalparty remains uncertain.

The negative indirect effect of person-to-state attachment on authoritarianism via social cohesion was also counterintuitive. One possible explanation may be found if the nature of attachment representations is considered. Although adult perceptions of self and other can be distorted by previous attachment experience, often do reflect the reality of the specific relationship (Owens et al. 1995). According to these researchers, the way current adult bonds are experienced is significantly impacted upon by representations of the past and the external demands of the present.

Bonds between individuals and collective entities, such as the national state, may follow similar principles. Considering the levels of dysfunctional provision and open hostility the modern Greek state has directed towards its citizens since its inception in the early nineteenth century (Ricks 2009), it may the case that those who feel either reluctant to engage with it (high avoidance) or apprehensive when they attempt to do so (high anxiety) mostly report real rather than defensively distorted characteristics of the relationship. Taking into account the fragmentation of formal social support, the lack of trust in social institutions, and the damage the country's international image has suffered in recent years, those individuals have also reasons to perceive low social cohesion. Interestingly, while they formed rather realistic perceptions of their social conditions, those individuals appeared less likely to endorse an authoritarian stance. On the other hand, those who presented high authoritarian attitudes were those who, despite all its serious historical failings, perceived a relatively trusting relationship with the Greek state and continued to have strong feelings of belonging and morale about their seriously strained and frustrating country. If such unrealistic perceptions constitute an unconscious defensive attempt to conceal a painful social reality, then authoritarian notions of all-powerful leaders and absolute social conventions can offer an illusion of comfort.

On the other hand, an alternative explanation could be that individuals with genuinely positive experiences 
with the state apparatus also genuinely perceived society as cohesive. However, the question remains why such socially content citizens adopt aggressive and intolerant socio-political views, which according to previous research, have been consistently linked with resentment and negative social experience (Rickert 1998; Sassoon 2007)? The above interpretation of the findings seems to suggest that the state attachment scale worked more like those scales of adult attachment assessing a specific relationship rather than those assessing generic working models (Collins and Read 1994). Although further validation is required, CFA results and the obtained associations between attachment-to-state and other study variables provide preliminary support for the validity of the instrument.

The current findings also confirm the important role of traumatic fear in the development of authoritarianism, a role repeatedly identified in history, but rarely evidenced in empirical research (Besel 1984; Sassoon 2007). As this study focused on traumatisation by austerity and socio-economic turbulence, it provided further evidence for the role of "economic" trauma in the emergence of far-right ideology and may be relevant to other major socio-political events currently unfolding across the globe. The recent appeal of nationalistic, xenophobic, and intolerant discourses to a large number of citizens after years of social inequality and economic hardship in Europe and the USA seem to be triggered by the experience of significant and unexpected threats. Such threats refer not only to people's livelihoods but also their social identities and become overwhelming as social institutions fail to contain them. Although economic hardship is not the only factor behind such an upsurge, it can interact with others, like uncontrolled immigration and challenges to national and democratic sovereignty, generating a toxic ideological mix.

While crisis-related traumatisation provided indirect links between attachment and authoritarianism, such traumatisation did not emerge as the result of particular perceptions of social cohesion, as it was initially hypothesised. As mentioned above, attachment may lie behind the link between posttraumatic stress and the extent to which society is perceived as cohesive. The current findings suggest that improving the quality of state provision and facilitating the exchange of interpersonal support are critical in reducing post-traumatic stress, distorted perceptions of social cohesion, and the adoption of authoritarian attitudes. The succession of Greek governments that managed the crisis and the troika of foreign lenders that imposed the harsh austerity seem to have operated in exactly the opposite direction. A similar approach has also been used in dealing with the economy in other Eurozone countries besides Greece. If policies towards enhancing the supportive capacity of social institutions and human relationships had been adopted instead, loss of trust in national and European institutions may have been prevented and the appeal of far-right parties across the continent may have been restrained. When threats to personal and social identities are buffered against, individuals feel less compelled to seek refuge in ideologies of total protection and irrefutable certainty.

The present study has a number of limitations. As attachment styles are understood to be relatively deep-seated and long-standing patterns of experience and behaviour in human relationships, it would not be unreasonable to expect that the styles of current participants had been formed before the economic crisis hit the country. However, it is also possible that such patterns, particularly in relation to the national state, were indeed affected by the crisis, including a crisis-induced surge in authoritarianism. Although the attachment-toauthoritarianism pathway model had a better fit than the alternative tested, the correlational nature of the study cannot really establish the direction of causality so findings need to be interpreted with caution. Moreover, it should be taken into account that demographic variables such as age, gender, or caring for dependents were associated with post-traumatic stress in the current sample (Sochos 2018) and may have impacted the current analyses. For example, as older individuals and those caring for dependants were found to suffer from relatively greater posttraumatic stress and as this is a rather young sample with $60 \%$ of participants having no dependants, the levels of post-traumatic stress recorded may have been distorted on those grounds. In addition, future studies should test the hypothesised model in representative samples in Greece and other countries undergoing socio-economic turmoil and validate further the adapted scales used improving their reliability when required. Finally, future psychosocial research on the recent trend towards reviving an idealised notion of the traditional nation-state could be informed by attachment theory and conceptualise such trend as a response to the dismantling of previously protective local social institutions by neoliberal globalisation. The present study can be thought of as a step in that direction.

Funding This study was funded by the Research Centre for Applied Psychology, University of Bedfordshire, UK (grant number 100).

\section{Compliance with Ethical Standards}

Ethical Approval All procedures performed involving human participants were in accordance with the ethical standards of the institutional and/or national research committee and with the 1964 Helsinki declaration and its later amendments or comparable ethical standards.

Informed Consent Informed consent was obtained from all individual participants included in the study.

Conflict of Interest The author declares that he has no conflict of interest. 


\section{Appendix}

\section{The Right-Wing Authoritarian Scale - Short Version}

1. Our country needs more powerful leaders, not more democracy.

[Original item: Our country needs a powerful leader, in order to destroy the radical and immoral currents prevailing in society today].

2. Our country needs free thinkers, who will have the courage to stand up against traditional ways, even if this upsets many people.

3. The "old-fashioned ways" and "old-fashioned values" still show the best way to live.

4. We have to be tougher against immigrants.

[Original item 13: Facts show that we have to be harder against crime and sexual morality, in order to uphold law and order].

5. The values of the traditional Greek family need to be protected before it is too late.

[Original item: God's law about abortion, pornography, and marriage must be strictly followed before it is too late, violations must be punished].

6. The society needs to show openness towards people thinking differently, rather than a strong leader, the world is not particularly evil or dangerous.

7. It would be best if newspapers were censored so that people would not be able to get hold of destructive and disgusting material.

8. The Greeks are great people but their progress is being sabotaged by the foreigners. [New item].

9. Our forefathers ought to be honoured more for the way they have built our society, at the same time we ought to put an end to those forces destroying it.

10. It is better to accept bad literature than to censor it. [Item 12 in original].

11. The situation in the society of today would be improved if immigrants [original: troublemakers] were treated with reason and humanity [Item 14 in original].

12. Protecting the fatherland is more important than protecting democracy. [New item].

Items of the original scale not included in the current version:

4. Our society would be better off if we showed tolerance and understanding for untraditional values and opinions.

8. Many good people challenge the state, criticize the church and ignore "the normal way of living".

10. People ought to put less attention to the Bible and religion, instead they ought to develop their own moral standards.

11. There are many radical, immoral people trying to ruin things; the society ought to stop them.

15. If the society so wants, it is the duty of every true citizen to help eliminate the evil that poisons our country from within.

\section{Social Group Attachment Scale}

\section{Avoidance}

1. I find it difficult to allow myself to depend on the Greek state.

4. I find it relatively easy to get close to the Greek state. (R). 9. I prefer not to depend on the Greek state or to have the Greek state depend on me.

11. I am comfortable not being close to the Greek state.

\section{Anxiety}

10. I often worry that the Greek state does not really accept me.

12. I often worry the Greek state will not always want me as a member.

16. I don't worry about being alone or not being accepted by the Greek state. $(\mathrm{R})$.

21. I sometimes worry that the Greek state does not value me as much as I value it.

24. I want to be close to the Greek state, but I find it difficult to trust it completely or to depend on it.

25. I do not often worry about being abandoned by the Greek state. (R).

Open Access This article is distributed under the terms of the Creative Commons Attribution 4.0 International License (http:// creativecommons.org/licenses/by/4.0/), which permits unrestricted use, distribution, and reproduction in any medium, provided you give appropriate credit to the original author(s) and the source, provide a link to the Creative Commons license, and indicate if changes were made.

Publisher's note Springer Nature remains neutral with regard to jurisdictional claims in published maps and institutional affiliations.

\section{References}

Adorno, T. W., Frenkel-Brunswik, E., Levinson, D. J., \& Sanford, R. N. (1950). The authoritarian personality. Oxford: Harpers.

Altemeyer, B. (1981). Right-wing authoritarianism. Winnipeg: University of Manitoba Press.

Altemeyer, B. (1996). The authoritarian spectre. Cambridge: Harvard University Press.

Altemeyer, B. (1998). The other "authoritarian personality.". In M. P. Zanna (Ed.), Advances in experimental social psychology (Vol. 30, pp. 47-91). San Diego: Academic Press.

Anagnostopoulos, D., \& Soumaki, E. (2013). The state of child and adolescent psychiatry in Greece during the international financial crisis: A brief report. European Child and Adolescent Psychiatry, 22(2), 131-134. https://doi.org/10.1007/s00787-013-0377-y.

Bar-Tal, D. (2000). Shared beliefs in a society: Social psychological analysis. Thousand Oaks: Sage Publications, Inc..

Bartholomew, K., \& Horowitz, L. M. (1991). Attachment styles among young adults: A test of a four-category model. Journal of 
Personality \& Social Psychology, 61, 226-244. https://oi.org/10. 1037/0022-3514.61.2.226.

BBC News (2013) Greece's Golden Dawn: 'Don't say a word or I'll burn you alive. Retrieved from http://www.bbc.co.uk/news/worldeurope-24363776. Accessed 10/12/16.

Besel, R. (1984). Political violence and the rise of Nazism. Cambridge: Yale University Press.

Bollen, K. A., \& Hoyle, R. H. (1990). Perceived cohesion: A conceptual and empirical examination. Social Forces, 69, 479-504.

Bonanno, G. A., \& Jost, J. T. (2006). Conservative shift among highexposure survivors of the September 11th terrorist attacks. Basic and Applied Social Psychology, 28(4), 311-323. https://doi.org/10. 1207/s15324834basp2804_4.

Bowlby, J. (1980). Attachment and loss. New York: Basic Books.

Bowlby, J. (1982). Attachment and loss: Attachment (Vol. 1). New York: Basic Books.

Brennan, K., Clark, C., \& Shaver, P. (1998). Self-report measures of adult romantic attachment. In J. Simpson \& W. Rholes (Eds.), Attachment theory and close relationships. New York: Guilford Press.

Bretherton, I., \& Munholland, K. A. (2008). Internal working models in attachment relationships: Elaborating a central construct in attachment theory. In J. Cassidy, P. R. Shaver, J. Cassidy, \& P. R. Shaver (Eds.), Handbook of attachment: Theory, research, and clinical applications (2nd ed., pp. 102-127). New York: Guilford Press.

Brislin, R. W. (1970). Back-translation for cross-cultural research. Journal of Cross-Cultural Psychology, 1(3), 185-216. https://doi. org/10.1177/135910457000100301.

Cassidy, J., \& Shaver, P. R. (2008). Handbook of attachment: Theory, research, and clinical applications (2nd ed.). New York: Guilford Press.

Chin, W. W., Salisbury, W. D., Pearson, A. W., \& Stollak, M. J. (1999). Perceived cohesion in small groups: Adapting and testing the perceived cohesion scale in a small-group setting. Small Group Research, 30(6), 751-766.

Cohrs, J. C. (2013). Threat and authoritarianism: Some theoretical and methodological comments. International Journal of Psychology, 48(1), 50-54. https://doi.org/10.1080/00207594.2012.732699.

Collins, N. L., \& Read, S. J. (1994). Cognitive representations of attachment: The structure and function of working models. In K. Bartholomew, D. Perlman, K. Bartholomew, \& D. Perlman (Eds.), Attachment processes in adulthood (pp. 53-90). London: Jessica Kingsley Publishers.

Cox, D. W., Buhr, E. E., Owen, J. J., \& Davidson, E. (2016). Linking partner emotional support, partner negative interaction, and trauma with psychological distress: Direct and moderating effects. Journal of Social and Personal Relationships, 33(3), 303-319. https://doi. org/10.1177/02654075574467.

Duckitt, J. (1989). Authoritarianism and group identification: A new view of an old construct. Political Psychology, 10, 63-84.

Durrheim, K. (1997). Theoretical conundrum: The politics and science of theorizing authoritarian cognition. Political Psychology, 18, 625-647.

Economou, M., Madianos, M., Peppou, L., Patelakis, A., \& Stefanis, C. (2013). Major depression in the era of economic crisis: A replication of a cross-sectional study across Greece. Journal of Affective Disorders, 145(3), 308-314. https://doi.org/10.1016/j.jad.2012.08.008.

Ein-Dor, T., Mikulincer, M., \& Shaver, P. R. (2011). Attachment insecurities and the processing of threat-related information: Studying the schemas involved in insecure people's coping strategies. Journal of Personality and Social Psychology, 101(1), 78-93. https://doi.org/ 10.1037/a0022503.

Feldman, S. (2003). Enforcing social conformity: A theory of authoritarianism. Political Psychology, 24(1), 41-74. https://doi.org/10.1111/ 0162-895X.00316.

Freshman, A. (2012). Financial disaster as a risk factor for posttraumatic stress disorder: Internet survey of trauma in victims of the Madoff ponzi scheme. Health \& Social Work, 37(1), 39-48. https://doi.org/ 10.1093/hsw/hls002.

Fromm, E. (1941). Escape from freedom. New York: Holt, Rinehart, \& Winston.

Gillath, O., \& Hart, J. (2010). The effects of psychological security and insecurity on political attitudes and leadership preferences. European Journal of Social Psychology, 40, 122-134. https://doi. org/10.1002/ejsp.614.

Gormley, B., \& Lopez, F. G. (2010). Authoritarian and homophobic attitudes: Gender and adult attachment style differences. Journal of Homosexuality, 57, 525-538. https://doi.org/10.1080/ 00918361003608715.

Griffin, D. W., \& Bartholomew, K. (1994). The metaphysics of measurement: The case of adult attachment. In K. Bartholomew \& D. Perlman (Eds.), Attachment processes in adulthood. (pp. 17-52). London: Jessica Kingsley Publishers.

Johns, L. E., Aiello, A. E., Cheng, C., Galea, S., Koenen, K. C., \& Uddin, M. (2012). Neighborhood social cohesion and posttraumatic stress disorder in a community-based sample: Findings from the Detroit neighborhood health study. Social Psychiatry and Psychiatric Epidemiology, 47(12), 1899-1906. https://doi.org/10.1007/s00127012-0506-9.

Kentikelenis, A., Karanikolos, M., Papanicolas, I., Basu, S., McKee, M., \& Stuckler, D. (2011). Health effects of financial crisis: Omens of a Greek tragedy. Lancet (British Edition), 378(9801), 1457-1458. https://doi.org/10.1016/S0140-6736(11)61556-0.

King, D. W., Orazem, R. J., Lauterbach, D., King, L. A., Hebenstreit, C. L., \& Shalev, A. Y. (2009). Factor structure of post-traumatic stress disorder as measured by the impact of event scale-revised: Stability across cultures and time. Psychological Trauma: Theory, Research, Practice, and Policy, 1(3), 173-187. https://doi.org/10.1037/ a0016990.

Klímová, H. (2011). The false we/the false collective self: A dynamic part of the social unconscious. In E. Hopper \& H. Weinberg (Eds.), The social unconscious in persons, groups, and societies, Vol 1: Mainly theory (pp. 187-208). London: Karnac Books.

Kreindler, S. A. (2005). A dual group processes model of individual differences in prejudice. Personality and Social Psychology Review, 9(2),90-107. https://doi.org/10.1207/ s15327957pspr0902_1.

Lê, F., Tracy, M., Norris, F. H., \& Galea, S. (2013). Displacement, county social cohesion, and depression after a large-scale traumatic event. Social Psychiatry and Psychiatric Epidemiology, 48(11), 17291741. https://doi.org/10.1007/s00127-013-0698-7.

Malley-Morrison, K. (2009). State violence and the right to peace: An international survey of the views of ordinary people (Vol. 1-4). Westport: Praeger Security International.

Markezinis, V. (2017) Is Greece's decline reversible? Retrieved February 17, 2017 from web site of political magazine Antivaro http://www. antibaro.gr/article/10110. Accessed 10/12/16.

Marlin, O. (2015). Psychoanalytic view of the totalitarian mentality: The case of the Czech experience. In E. Hopper \& H. Weinberg (Eds.), The social unconscious in persons, groups, and societies: Volume 2: Mainly Foundation matrices (pp. 81-100). London: Karnac Books.

Mayseless, O., \& Popper, M. (2007). Reliance on leaders and social institutions: An attachment perspective. Attachment \& Human Development, 9(1), 73-93.

McCann, S. J. H., \& Stewin, L. I. (1987). Threat, authoritarianism, and the power of U.S. presidents. Journal of Psychology, 121, 149-157.

Mesogianews (2015). Where Golden Dawn got most of its votes. Retrieved from http://www.mesogianews.gr/politics. Accessed 10/ $12 / 16$.

Mikulincer, M., \& Shaver, P. R. (2001). Attachment theory and intergroup bias: Evidence that priming the secure base schema attenuates negative reactions to out-groups. Journal of Personality and Social Psychology, 81, 97-115. https://doi.org/10.1037/0022-3514.81.1.97. 
Mikulincer, M., \& Shaver, P. R. (2007). Attachment in adulthood: Structure, dynamics, and change. New York: Guilford Press.

Mikulincer, M., \& Shaver, P. R. (2009). An attachment and behavioral systems perspective on social support. Journal of Social and Personal Relationships, 26(1), 7-19. https://doi.org/10.1177/ 0265407509105518.

Mystakidou, K., Tsilika, E., Parpa, E., Galanos, A., \& Vlahos, L. (2007). Psychometric properties of the impact of event scale in Greek cancer patients. Journal of Pain Symptom Management, 33(4), 454-461. https://doi.org/10.1016/j.jpainsymman.2006.09.023.

Oesterreich, D. (2005). Flight into security: A new approach and measure of the authoritarian personality. Political Psychology, 26(2), 275297. https://doi.org/10.1111/j.1467-9221.2005.00418.x.

Onraet, E., \& Van Hiel, A. (2013). When threat to society becomes a threat to oneself: Implications for right-wing attitudes and ethnic prejudice. International Journal of Psychology, 48(1), 25-34. https://doi.org/10.1080/00207594.2012.701747.

Owens, G., Crowell, J. A., Pan, H., Treboux, D., O'Connor, E., \& Waters, E. (1995). The prototype hypothesis and the origins of attachment working models: Adult relationships with parents and romantic partners. Monographs of the Society for Research in Child Development, 60(2-3), 216-233. https://doi.org/10.2307/1166180.

Pierrakakis, K. (2017, May 13) Crisis or decline? Retrieved March, 2018 from web site of newspaper Ta Nea http://www.tanea.gr/opinions/ all-opinions/article/5445403. Accessed March 2018.

Public Opinion Analysis Sector of the European Commission. (2012). European citizenship, Standard Eurobarometer 78. Brussels: Author.

Ray, L. (2006). Mourning, melancholia and violence. In D. Bell (Ed.), Memory, trauma and world politics (pp. 30-45). Basingstoke: Palgrave.

Rickert, E. J. (1998). Authoritarianism and economic threat: Implications for political behavior. Political Psychology, 19(4), 707-720. https:// doi.org/10.1111/0162-895X.00128.

Ricks, D. (2009). The making of modern Greece: Nationalism, romanticism, and the uses of the past. London: Routledge.

Rom, E., \& Mikulincer, M. (2003). Attachment theory and group processes: The association between attachment style and group-related representations, goals, memories, and functioning. Journal of Personality and Social Psychology, 84, 1220-1235.

Sales, S. M. (1973). Threat as a factor in authoritarianism: An analysis of archival data. Journal of Personality and Social Psychology, 28(1), 44-57. https://doi.org/10.1037/h0035588.

Sassoon, D. (2007). Mussolini and the rise of fascism. UK: HarperCollins.

Schofield, G., \& Beek, M. (2014). The Secure Base model: Promoting attachment and resilience in foster care and adoption. London: BAAF ISBN 9781907585838
Sijtsma, K., \& van der Ark, L. A. (2015). Conceptions of reliability revisited and practical recommendations. Nursing Research, 64(2), 128-136. https://doi.org/10.1097/NNR.0000000000000077.

Smith, E. R., Murphy, J., \& Coats, S. (1999). Attachment to groups: Theory and management. Journal of Personality and Social Psychology, 77, 94-110. https://doi.org/10.1037/00223514.77.1.94.

Sochos, A. (2014). Attachment security and the social world. Basingstoke: Palgrave.

Sochos, A. (2018). Post-traumatic stress during the Greek economic crisis: Is there evidence for mass traumatisation? Analyses of Social Issues and Public Policy, 18, 265-283.

Sztompka, P. (2000). Cultural trauma: The other face of social change. European Journal of Social Theory, 3, 449-460. https://doi.org/10. 1177/136843100003004004.

Tzogopoulos, G. (2016). The Greek crisis in the media: Stereotyping in the international press. London: Routledge.

Van Hiel, A., Duriez, B., \& Kossowska, M. (2006). The presence of leftwing authoritarianism in Western Europe and its relationship with conservative ideology. Political Psychology, 27(5), 769-793. https://doi.org/10.1111/j.1467-9221.2006.00532.x.

Vilchinsky, N., Findler, L., \& Werner, S. (2010). Attitudes toward people with disabilities: The perspective of attachment theory. Rehabilitation Psychology, 55, 298-306.

Weber, C., \& Federico, C. M. (2007). Interpersonal attachment and patterns of ideological belief. Political Psychology, 28(4), 389-416. https://doi.org/10.1111/j.1467-9221.2007.00579.x.

Weise, D. R., Pyszczynski, T., Cox, C. R., Arndt, J., Greenberg, J., Solomon, S., \& Kosloff, S. (2008). Interpersonal politics the role of terror management and attachment processes in shaping political preferences. Psychological Science, 19, 448-455. https://doi.org/10. 1111/j.14679280.2008.02108.x.

Weiss, D., \& Marmar, C. (1997). The impact of event scale-Revised. In J. P. Wilson \& T. M. Keane (Eds.), Assessing psychological trauma and PTSD (pp. 399-411). New York: Guilford Press.

Wolf, E. J., Harrington, K. M., Clark, S. L., \& Miller, M. W. (2013). Sample size requirements for structural equation models: An evaluation of power, bias, and solution propriety. Educational and Psychological Measurement, 73(6), 913-934. https://doi.org/10. 1177/0013164413495237.

Woodhouse, S., Ayers, S., \& Field, A. P. (2015). The relationship between adult attachment style and post-traumatic stress symptoms: A metaanalysis. Journal of Anxiety Disorders, 35, 103-117. https://doi.org/ 10.1016/j.janxdis.2015.07.002.

Yellin, J., \& White, K. (2012). Shattered states: Disorganised attachment and its repair. London: Karnac Books.

Zakrisson, I. (2005). Construction of a short version of the right-wing authoritarianism (RWA) scale. Personality and Individual Differences, 39(5), 863-872. https://doi.org/10.1016/j.paid.2005. 02.026 . 